\section{Receptive music interventions improve apathy and depression in elderly patients with dementia}

\author{
Massimiliano Massaia, ${ }^{1}$ \\ Alessandro Reano, ${ }^{1}$ Chiara Luppi, ${ }^{1}$ \\ Francesca Santagata, ${ }^{1}$ \\ Margherita Marchetti, ${ }^{1}$ \\ Giovanni Carlo Isaia ${ }^{2}$ \\ ${ }^{1}$ Department of Geriatrics, AOU Città \\ della Salute e della Scienza, Torino; \\ ${ }^{2}$ Unit of Geriatrics and Metabolic Bone \\ Disease, Molinette Hospital and School \\ of Geriatric Medicine, University of \\ Torino, Italy
}

\section{Abstract}

Individuals with dementia and their families often experience poor quality of life due to patient's behavioral and psychological symptoms. Increasing evidence has mounted on the potential role of music in improving social, emotional and cognitive skills. In the present study we aim to investigate whether a receptive music intervention might reduce apathy and depression in elderly patients with Alzheimer's disease (AD) or vascular dementia (VaD) and improve their caregivers' burden. Among patients attending to a Memory Clinic, we have enrolled $48 \mathrm{AD}$ or VaD elderly subjects. They were divided into two groups on the basis of family agreement to musictherapy. The experimental group $(n=15)$ was asked to listen to a 80 -minute audio $\mathrm{CD}$, for at least 15 minutes per day, at least once a week, for three months. The overall sample was evaluated at baseline, at week 4 and at week 12 through the Mini Mental State Examination (MMSE), the CornelBrown Scale QoL in Dementia (CBSQoLD) and the Apathy Evaluation Scale (AES); caregiver stress was assessed using the Caregiver Burden Inventory (CBI). Apathy and depression were significantly improved among patients treated with music interventions compared to control group (treatment effect $=43.667 ; \mathrm{P}<0.001$ and treatment effect $=61.238 ; \mathrm{P}<0.001$ respectively). Caregiver burden was significantly reduced after three months of receptive music approach (treatment effect $=15.759 ; \mathrm{P}<0.001)$. The results of this study are consistent with the efficacy of receptive music interventions on improving apathy and depression in $\mathrm{AD}$ or $\mathrm{VaD}$ elderly patients and lowering associated caregiver's burden.

\section{Introduction}

Research reports estimate that the number of people with dementia is steadily increasing and rise as the population ages. 4.8 million of people worldwide are living with dementia in 2015. This number is expected to almost double every 20 years, with an increase in low and middle-income countries. In contrast with other conditions, the impact of dementia on patients and their family lives comes mainly from years lived with disability due to cognitive, functional and behavioral deterioration, rather than years of life lost from premature mortality. ${ }^{1}$ Within this contest behavioral and psychological symptoms of dementia (BPSD) has a great relevance.

BPSD occur in up to $80 \%$ of patients with dementia. Since behavioral disturbances are among the primary causes of institutionalization and caregivers' burden, many studies have been focused on this topic. National and international guidelines often recommend that the first course of action ought to be implementation of non-pharmacological interventions prior to the initiation of any psychotropic medication therapy. 2,3

Behaviors may be positive or negative in terms of level of activity and agitation. Common negative behaviors are apathy and depression.

Apathy is a frequent presenting symptom of dementia. ${ }^{4}$ It is highly prevalent across different forms and stages of cognitive impairment, including in mild cognitive impairment (MCI), Alzheimer's disease (AD), frontotemporal dementia (FTD), and vascular dementia, as well as in other neurodegenerative and psychiatric disorders such as Parkinson's disease (PD), schizophrenia, stroke, multiple sclerosis, traumatic brain injury, and major depression. It has been increasingly described as a syndrome too. ${ }^{5}$

Recently it was defined as a disorder of motivation in at least two or three domains (self- initiated or environment-stimulated goal-directed behavior (cognitive goaldirected behavior, including a loss of ideas and curiosity and emotional goal-directed behavior, including loss of spontaneous emotion or emotional responsiveness), that persists over time, thus impairing subject's functional status. ${ }^{6,7}$

Although DSM-IV included this syndrome (Personality change due to medical condition, apathetic type), it does not appear in the currently proposed version of DSM-V. An oversight that will obstruct recognition and treatment of the apathy, often underreported or misdiagnosed as sadness and depression, even if it is largely known that apathy is a distinct neuropsychiatric syn-
Correspondence: Margherita Marchetti, SC Geriatria e Malattie Metaboliche dell'Osso, A.O. Città della Salute e della Scienza di Torino, C.so Bramante 88/90, 10126 Torino, Italy.

Tel.: +39.011 .6335328$

Fax: +39.011 .6636033 .

E-mail: margherita.marchetti@hotmail.it

Key words: Dementia; apathy; depression; music interventions; elderly.

Contributions: the authors contributed equally.

Conflict of interest: the authors declare no potential conflict of interest.

Received for publication: 21 December 2017. Revision received: 24 February 2018 , Accepted for publication: 26 February 2018.

This work is licensed under a Creative Commons Attribution-NonCommercial 4.0 International License (CC BY-NC 4.0).

CCopyright M. Massaia et al., 2018

Licensee PAGEPress, Italy

Geriatric Care 2018; 4:7248

doi:10.4081/gc.2018.7248

drome. It is thought to have a proper neuroanatomical correlation, involving different anatomical structures for each of the three apathy domains. ${ }^{89}$ Cholinergic, dopaminergic, serotonergic, and GABAergic neurotransmitters have all been linked to apathy in AD. ${ }^{10}$ Cholinergic deficiency may affect limbic systems, while dopamine deficiency affects the reward system. ${ }^{11-14}$ Elevated plasma GABA levels have been associated with apathy in $\mathrm{AD} .{ }^{15}$

Apathy frequency ranges differ across patient populations, settings and definitions from 55 to $80 \%$ in study using the NeuroPsychiatry Inventory (NPI) and from 37 to $86 \%$ in study using specific apathy scales (AES). ${ }^{16}$

Dementia and depression are the most common psychiatric syndromes in older age: their diagnosis remains clinically challenging since the two conditions have a complicated relationship. Cognitive changes are common in the context of depression, and mood symptoms frequently accompany cognitive disorders. This comorbidity represents a challenge for clinicians assessing older, functionally impaired patients with signs and symptoms of mood and cognitive disorders. ${ }^{17}$

The diagnostic criteria for major depression in the Diagnostic and Statistical Manual of Mental Disorders, fifth edition (DSM-5), require the presence of either sadness or anhedonia with a total of five or 
more symptoms over a 2 -week period. Low mood may be less common in older adults with depression than in younger adults with the disorder, whereas irritability, anxiety and somatic symptoms may be more common. Psychosocial stressors such as the death of a loved one may trigger a depressive episode, although transient reactions to major losses can resemble depression. ${ }^{18}$ Overall, latelife depression has distinctive features that allow its differentiation from depressive disorders occurring at a younger age. ${ }^{19}$

Age-related and disease-related changes, including arteriosclerosis, chronic inflammation, hormonal, and immune modifications, may affect the integrity of frontostriatal circuits as well as the amygdala and the hippocampus, ultimately increasing the vulnerability to depression. ${ }^{20}$ In addition, age-related psychosocial stressors including poor socioeconomic status, disability, and social isolation are significant risk factors for depression. ${ }^{21}$ Vegetative symptoms and impairments of executive functions, attention, information processing, psychomotor speed, and working memory are common. In particular, subcortical vascular chang es play a major role in the pathophysiology of late-life depression leading to the conceptualization of vascular depression, as defined by the results of magnetic resonance imaging (MRI). ${ }^{22,23}$

Risk of suicide is approximately 2-fold higher in the elderly, especially in older males, compared with the general population. ${ }^{24}$

Recent studies concluded that depressive symptoms may represent a prodrome of dementia or that the two conditions share common causes. No support was found for the construct that depressive symptoms are a risk factor for dementia. ${ }^{25}$

Notably, depressive symptoms have been reported in $30 \%-50 \%$ of patients with $\mathrm{AD}$ and are especially common at the prodromal stage. ${ }^{26}$ Overt major depression can be diagnosed in $10 \%$ of AD patients, mostly during the early to moderately impaired stage $^{27}$ and in up to $50 \%$ of patients with vascular dementia. ${ }^{28,29}$

Nearly a third of people with mild cognitive impairment have depression. ${ }^{30}$

Currently, various mechanisms have been proposed to explicate the association between depression and dementia. First, there is significant evidence indicating that vascular disease is the primary link. ${ }^{31}$ In particular, vascular changes in the frontostriatal brain regions have been linked to both depressive symptoms and cognitive impairment. . $^{32-34}$

In addition, increased cortisone levels, a biochemical alteration frequently observed in depressive disorders, can lead to worsen- ing hippocampal atrophy associated with cognitive deficits. ${ }^{35,36}$ Notably, atrophy of the hippocampus is a well-characterized brain alteration detected both in $\mathrm{AD}^{37}$ and in patients with depression. ${ }^{38,39}$ Interestingly, evidence indicates that depression might lead to an increased disequilibrium in terms of $\mathrm{Ab}$ production and/or clearance.

With respect to pharmacological approach to both apathy and depression, convincing pharmacological strategies for managing apathy are yet to be developed. Previously reported benefits of AChEIs and memantine were not replicated in recent studies. Antidepressants had mixed results with positive effects found only for agomelatine. For some pharmacotherapies, including antipsychotic review, improvement of apathy was found only in combination with non pharmacological approaches. ${ }^{40-43}$

As reviewed recently by Leong, ${ }^{44}$ several randomized placebo-controlled interventions reported negative outcomes for antidepressant efficacy in dementia. Well-controlled studies, systematic reviews, and meta-analy$\operatorname{ses}^{45-47}$ have shown no reliable and convincing efficacy of antidepressants in patients with dementia and co-occurring depressive disorders. Even the addition of a cholinesterase inhibitor in depressed patients showed only a small effect on concurrent cognitive impairment and on the conversion rate to dementia syndrome but with increased risk of recurrence of depression.

The sobering results of pharmacological trials also highlight the need to consider alternative non-pharmacological treatments; for instance musictherapy. ${ }^{48}$

The use of music and its elements (rhytm, harmony, sound, melody) is gaining greater acceptance in different medical settings. It is quite challenging to offer an unequivocal definition of music therapy as music therapy is a fusion of music and therapy and is at once an art, a science and an interpersonal process. ${ }^{49}$

The American Music Therapy Association (AMTA) defines music therapy as "the clinical and evidence-based use of music interventions to accomplish individualized goals within a therapeutic relationship by a credentialed professional who has completed an approved music therapy program. ${ }^{50}$

Research has begun to demonstrate the beneficial effects of music therapy in ameliorating stress and mood dysfunctions associated with specific conditions, such as multiple sclerosis, ${ }^{51}$ miocardial infarction ${ }^{52}$ and cancer. ${ }^{53}$

Music therapy approach was investigated in patient with dementia for the management of agitation, ${ }^{54}$ aggression, ${ }^{55}$ anxiety and psychosis. However, the evidence supporting the effectiveness of music therapy was limited by moderate, but significant, heterogeneity, probably related to the variability of the intervention (e.g., type of music, active involvement, such as singing/playing a musical instrument and dancing, or passive involvement, such as listening) and the heterogeneity of the patient population in terms of the severity of dementia and the type of dementia. ${ }^{56} \mathrm{~A}$ recent Cochrane review underlined that providing people with dementia with at least five sessions of a music-based therapeutic intervention probably reduces depressive symptoms but has little or no effect on agitation or aggression. There may also be little or no effect on emotional well-being or quality of life, overall behavioural problems and cognition. Authors were uncertain about effects on anxiety or social behaviour, and about any long-term effects, since the methodological quality of the studies varied and were at high risk of bias. ${ }^{57}$

Providing people with dementia with at least five sessions of a music-based therapeutic intervention probably reduces depressive symptoms but has little or no eff ect on agitation or aggression. There may also be little or no effect on emotional well-being or quality of life, overall behavioural pr oblems and cognition. We are uncertain about ef fects on anxiety or social behaviour, and about any long-term effects. Future studies should employ larger sample sizes, and include all important outcomes, in particular positive outcomes such as emotional well-being and social outcomes. Future studies should also examine the duration of ef fects in relation to the overall duration of treatment and the number of sessions.

Providing people with dementia with at least five sessions of a music-based therapeutic intervention probably reduces depressive symptoms but has little or no eff ect on agitation or aggression. There may also be little or no effect on emotional well-being or quality of life, overall behavioural pr oblems and cognition. We are uncertain about ef fects on anxiety or social behaviour, and about any long-term effects. Future studies should employ larger sample sizes, and include all important outcomes, in particular positive outcomes such as emotional well-being and social outcomes. Future studies should also examine the duration of ef fects in relation to the overall duration of treatment and the number of sessions. Providing people with dementia with at least five sessions of a music-based therapeutic intervention probably reduces depressive symptoms but has little or no eff ect on agitation or aggression. There may also be little or no effect on emotional well-being or quality of life, overall behavioural pr oblems and cognition. We are uncertain about ef fects on anxiety or social 
behaviour, and about any long-term effects. Future studies should employ larger sample sizes, and include all important outcomes, in particular positive outcomes such as emotional well-being and social outcomes. Future studies should also examine the duration of ef fects in relation to the overall duration of treatment and the number of sessions.

Providing people with dementia with at least five sessions of a music-based therapeutic intervention probably reduces depressive symptoms but has little or no eff ect on agitation or aggression. There may also be little or no effect on emotional well-being or quality of life, overall behavioural pr oblems and cognition. We are uncertain about ef fects on anxiety or social behaviour, and about any long-term effects. Future studies should employ larger sample sizes, and include all important outcomes, in particular positive outcomes such as emotional well-being and social outcomes. Future studies should also examine the duration of ef fects in relation to the overall duration of treatment and the number of sessions.

Within this contest it emerges quite clearly that the prevalent music interventions are those finalized to the improvement of agitation and anxiety. Conversely, the role of music approach on apathy and depression associated to dementia have been poorly investigated.

With the present study we aim to look for evidence in using musictherapy to reduce apathy and depression in dementia and to decrease the caregiver burden in a home setting.

\section{Materials and Methods}

This prospective cohort study aimed at evaluating whether an intervention of music medicine in home-setting might reduce apathy and depressive symptoms in elderly demented people, aged 65 or older and improve the caregiver burden. The primary endpoint was the change from baseline to week 12 in the AES-C, CBS-QoLD and CBI.

Secondary objectives were to assess any cognitive and pharmacological change between the study groups.

During the period November 2013 June 2014 , 48 patients with dementia, consecutively attending the Cognitive Disorder Clinic of Department of Geriatrics, Città della Salute e della Scienza - University Hospital in Turin (Italy), have been recruited for this study. A written informed consent was provided for all participants.

Alzheimer's disease (AD) was diagnosed according to NIA-AA criteria. ${ }^{58}$ Vascular dementia (VaD) was defined according to VASCOG statement ${ }^{59}$ and DSM V criteria ${ }^{60}$ for VaD. Subjects affected by other types of dementia, whom with BPSD characterized by positive symptoms (agitation, anxiety, irritability, disinhibition, euphoria, delusions, hallucinations) or with a reduction in hearing ability were excluded. Elderly people who didn't have a caregiver or lived in nursing homes were not admitted too. We defined a caregiver as a person spending at least 4 hours per day at least 4 days per week with the patient and who is knowledgeable about the patient's daytime and nighttime behaviors.

For each subject demographic variables (age/gender/education) were collected. A comprehensive assessment of patient's medical history (cognitive disease duration/ time since diagnosis/prescribed anti-depressive and anxiolytic medications) was obtained using the documentation provided by the subject and direct interview obtained by the participants.

A comprehensive psychometric assessment was carried out at baseline, at week 4 and at week 12. Cognitive status was evaluated through the age-and education-adjusted Mini Mental State Examination (MMSE), ${ }^{61}$ a widely used 11 -item test of orientation, attention, memory, language and visual-spatial skills. To provide a global measure of apathy, the Clinician version Apathy Evaluation Scale (AES-C) ${ }^{62}$ was administered as a semi structured interview. The AES-C is an 18-item scale, evaluating the behavioral, cognitive, and emotional aspects of goal-directed behavior during the past 4 weeks. To assess depression and quality of life in patient with dementia, the 19-item Cornell-Brown Scale QoL in dementia (CBS-QoLD) was used. $^{63}$ Information was elicited through a joint semi structured interview, with the patient and the caregiver, focused on sign and symptoms of depression occurring the week preceding the visit. The 24-item Caregiver Burden Inventory $(\mathrm{CBI})^{64}$ was used to investigate caregiver's feelings and responses to the demands of care. It is a self-administered test measuring caregiver burden through 5 subscale: A time dependence (time demands and restrictions that caregiving might impose to caregiver), $\mathrm{B}$ developmental (description of the caregiver's feeling of being excluded respect to the life opportunities of his peers), C-D and E physical, social (caregiver's negative feelings toward his care receiver, which may result from patient's unpredictable and bizarre behavior) and emotional burden respectively. Each item was rated for severity on a scale of 0 (not at all disruptive) - 4 (disruptive).

The study population was devided into an experimental $(\mathrm{n}=15)$ and a control $(n=33)$ group, on the basis of the caregiver's agreement to musictherapy.

A 80-minute - audio CD was pre-taped, with the collaboration of a music therapist. It included 20 music compositions, different types of musical stimuli leading to emotional modifications. The CD started with opening slow-rhythm melodies, which help transition the patient to own discomfort and distress. A receptive approach was used during the music intervention, since patients were asked just to listen to music. This technique involved the pre-composed playlist for progressively achieving relaxation, guided reminiscence and change of mood state. The last CD songs were thought to close the therapy, with a happy atmosphere.

Music was delivered to the 15 patients assigned to the experimental group over at least 15 minutes- daily sessions, at least once a week for three months; while the control subjects received standard care.

The Software IBM-SPSS 19.0 for Windows was used for the statistical analysis. For continuous variables the mean and the standard deviation (SD) were calculated. Frequency analysis was used for categorical variables. The t-test for paired data was used to compare continuous variables. ANOVA was calculated to test hypothesis of equity of means.

To compare the scale scores obtained for the study groups at baseline, 4 and 12 weeks, a generalized linear model for repeated measures was used.

Statistical significance was established at $\alpha=0.05$

\section{Results}

In this study, 48 patients were included; 38 were females $(79 \%)$ and 10 were males (21\%). The average age was $80.6 \pm 5.8$ years; the average years of schooling was $5.42 \pm 2.98$. The average MMSE score at baseline was 17.2 \pm 6.07 ; the average AES, CORNELL scale and CBI scores at baseline are shown in Table 1. The average of the total caregiving time was $11.96 \pm 8.92$ hours per day.

At baseline, the time elapsed from the onset of symptoms, the time from diagnosis, years of education, MMSE, CORNELL (CBS-QoLD) scale and CBI scores were not significantly different between music and control groups respectively (Table 2). Otherwise age and AES score were significantly different between the two groups $($ Age $=$ P $0.040 ;$ AES $=$ P 0.006) so they have been analyzed as possible confounders during data elaboration. 
There was a significant constant music effect on apathy reduction (treatment effect $=43.677 ; \quad 95 \% \mathrm{CI}=-18.13 ; \quad-9.2$; $\mathrm{P}<0.001)$ and depressive symptoms decrease (treatment effect $=61.238 ; 95 \% \mathrm{CI}=7.59 ; 15.38$; $\mathrm{P}<0.001)$ among subjects treated with music therapy (Tables 2 and 3; Figures 1 and 2).

Importantly, a significant decline of the caregiver burden was found (treatment effect $=15.759 ; 95 \% \mathrm{CI}=2.39 ; 5.77 ; \mathrm{P}<0.01)$ in the music group (Table 4; Figure 3). The caregiver burden significantly dereased

Table 1. Mean variables and score of control and treated groups at baseline.

\begin{tabular}{|c|c|c|c|c|c|}
\hline & Control group & Treated group & Treatment effect & $95 \% \mathrm{CI}$ & P-value \\
\hline Age & $81.72 \pm 5.34$ & $78.13 \pm 6.312$ & 4.167 & $78.91 ; 82.30$ & 0.040 \\
\hline Time from diagnosis (months) & $20.12 \pm 21.117$ & $26.2 \pm 15.576$ & 0.992 & $16.33 ; 27.71$ & 0.324 \\
\hline Time from symptoms oneset (months) & $55.58 \pm 30.787$ & $58 \pm 26.79$ & 0.069 & $47.82 ; 64.85$ & 0.794 \\
\hline Years of education & $5.27 \pm 3.214$ & $5.73 \pm 2.463$ & 0.242 & $4.55 ; 6.28$ & 0.625 \\
\hline AES 1 & $16.36 \pm 5.572$ & $22.4 \pm 8.692$ & 8.427 & $16.16 ; 20.34$ & 0.006 \\
\hline Cornell 1 & $13.12 \pm 6.035$ & $12 \pm 5.099$ & 0.390 & $11.11 ; 14.43$ & 0.535 \\
\hline Total caregiving hours & $11.67 \pm 9.051$ & $12.6 \pm 8.903$ & 0.111 & $9.37 ; 14.55$ & 0.741 \\
\hline CBI TOT 1 & $15.15 \pm 10.788$ & $14.67 \pm 14.146$ & 0.017 & $11.58 ; 18.42$ & 0.897 \\
\hline MMSE & $17.7 \pm 5.995$ & $15.51 \pm 6.181$ & 1.346 & $15.25 ; 18.78$ & 0.252 \\
\hline
\end{tabular}

Table 2. AES mean score. Higher is better.

\begin{tabular}{|c|c|c|c|c|c|c|}
\hline & AES & $\mathbf{N}$ & Mean score (mean \pm SD) & B & CI 95\% (a1;a2) & P-value \\
\hline Control & $\begin{array}{l}\text { Basal } \\
1 \text { month } \\
3 \text { month }\end{array}$ & 33 & $\begin{array}{c}16.36 \pm 5.572 \\
14.94 \pm 5.5 \\
14 \pm 5.368\end{array}$ & & & \\
\hline Treated & $\begin{array}{l}\text { Basal } \\
1 \text { month } \\
3 \text { month }\end{array}$ & 15 & $\begin{array}{c}22.4 \pm 8.692 \\
24.73 \pm 9.543 \\
27.67 \pm 10.033\end{array}$ & $\begin{array}{l}-6.04 \\
-9.79 \\
-13.67\end{array}$ & $\begin{array}{c}-10.22 ;-1,85 \\
-14.17 ;-5.42 \\
-18.13 ;-9.2\end{array}$ & $\begin{array}{l}0.006 \\
<0.001 \\
<0.001\end{array}$ \\
\hline Total & $\begin{array}{l}\text { Basal } \\
1 \text { month } \\
3 \text { month }\end{array}$ & 48 & $\begin{array}{c}18.25 \pm 7.186 \\
18 \pm 8.293 \\
18.27 \pm 9.518\end{array}$ & & & \\
\hline
\end{tabular}

Table 3. Cornell mean score. Lower is better.

\begin{tabular}{|c|c|c|c|c|c|c|}
\hline & Cornell & $\mathbf{N}$ & Mean score (mean \pm SD) & B & CI 95\% (a1;a2) & P-value \\
\hline Control & $\begin{array}{l}\text { Basal } \\
1 \text { month } \\
3 \text { month }\end{array}$ & 33 & $\begin{array}{l}13.12 \pm 6.035 \\
15.45 \pm 6.165 \\
16.48 \pm 6.843\end{array}$ & & & \\
\hline Treated & $\begin{array}{l}\text { Basal } \\
1 \text { month } \\
3 \text { month }\end{array}$ & 15 & $\begin{array}{c}12 \pm 5.099 \\
6.6 \pm 4.323 \\
5 \pm 4.456\end{array}$ & $\begin{array}{c}1.12 \\
8.86 \\
11.49\end{array}$ & $\begin{array}{c}-2.49 ; 4.74 \\
5.30 ; 12.40 \\
7.59 ; 15.38\end{array}$ & $\begin{aligned} & 0.53 \\
< & 0.001 \\
< & 0.001\end{aligned}$ \\
\hline Total & $\begin{array}{l}\text { Basal } \\
1 \text { month } \\
3 \text { month }\end{array}$ & 48 & $\begin{array}{c}12.77 \pm 5.729 \\
12.69 \pm 6.975 \\
12.9 \pm 8.169\end{array}$ & & & \\
\hline
\end{tabular}

Table 4. CBI mean score. Lower is better.

\begin{tabular}{|c|c|c|c|c|c|c|}
\hline & CBI total & $\mathbf{N}$ & Mean score (mean \pm SD) & B & CI 95\% (a1;a2) & P-value \\
\hline Control & $\begin{array}{l}\text { Basal } \\
1 \text { month } \\
3 \text { month }\end{array}$ & 33 & $\begin{array}{l}15.15 \pm 10.788 \\
16.64 \pm 11.399 \\
17.06 \pm 11.608\end{array}$ & & & \\
\hline Treated & $\begin{array}{l}\text { Basal } \\
1 \text { month } \\
3 \text { month }\end{array}$ & 15 & $\begin{array}{l}14.67 \pm 14.146 \\
13.67 \pm 13.813 \\
11.87 \pm 13.136\end{array}$ & $\begin{array}{l}0.49 \\
3.97 \\
4.19 \\
\end{array}$ & $\begin{array}{c}-6.98 ; 7.95 \\
2.67 ; 6.61 \\
2.39 ; 5.77\end{array}$ & $\begin{array}{l}0.89 \\
0.01 \\
0.01\end{array}$ \\
\hline Total & $\begin{array}{l}\text { Basal } \\
1 \text { month } \\
3 \text { month }\end{array}$ & 48 & $\begin{array}{c}15 \pm 11.785 \\
15.71 \pm 12.134 \\
15.44 \pm 12.209\end{array}$ & & & \\
\hline
\end{tabular}


considering each one of the $\mathrm{CBI}$ subgroups (A: time -dependence burden; B: developmental burden; $\mathrm{C}$ : physical burden; $\mathrm{D}$ : social burden), except the E (emotional burden) (Figures 4 and 5).

No significant changes were observed in subjects' pharmacological therapies.

\section{Discussion}

This study analysed the effects of music therapy on cognitive and behavioural problems, in particular apathy and depression in patients with Alzheimer's type or vascular dementia.

The study results showed the trend congruent with our hypothesis that this type of intervention has positive impact on apathy and depression; similar results have been reported in a recent Cochrane review. ${ }^{57}$

In literature music therapy was found to improve delusions, hallucinations, irritability, and agitation in moderate dementia, probably due to the higher intensity of symptoms, often triggered by environmental stressfull conditions. Music is a pleasant stimulus, especially when it is adapted to one's personal preferences, and it can evoke positive emotions. It also affects the endocrine and autonomic nervous systems by decreasing stress-related activation of the adrenomedullary and parasympathetic nervous systems. ${ }^{64}$ To our knowledge our study is one of the few that explore the effect of music intervention on apathy and any variation on caregiver burden associated to behavioural symptoms usually not considered so stressfull.

Regarding cognitive function, our approach was finalized mainly to a global assessment; no statistical differences were found in MMSE between the two groups. One limitation of our study design was not to explore each cognitive function in relation to music intervention despite evidence that recognition of the emotions associated with music seems to be preserved in patients with AD. ${ }^{65,66}$ Futhermore, music enhances encoding of verbal information in healthy elderly individuals and in patients with AD. ${ }^{67}$ This may be explained by the fact that music alters the executive, associative, and auditory networks involved in brain plasticity and learning. ${ }^{68}$ In addition, music has been observed to improve naming ability and speech fluency and content, as well as the drive to communicate, in patients with dementia.In fact, music training leads to recruitment of right hemisphere areas involved in speech processing, leading to improved language comprehension. ${ }^{69,70}$

Another limitation of our study is not have assessed whether gains on apathy and depressive symptoms reduction, and on caregiver burden decrease might remain in long term. Although some suggest that the effects of these interventions may be persistent, ${ }^{71}$ cognitive improvements may even

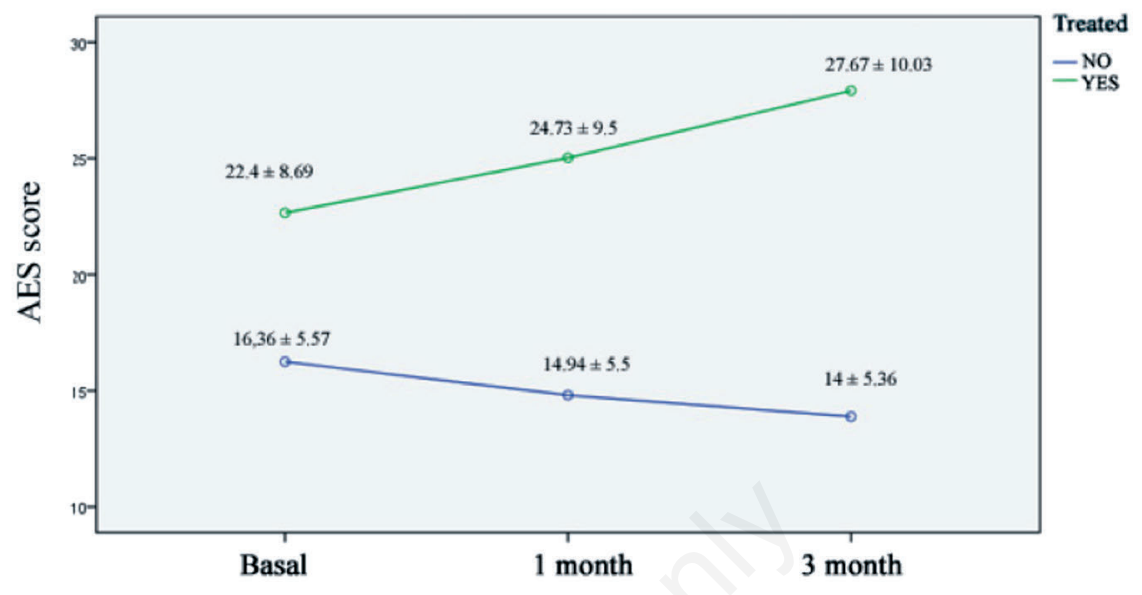

Figure 1. AES mean score. Higher is better.

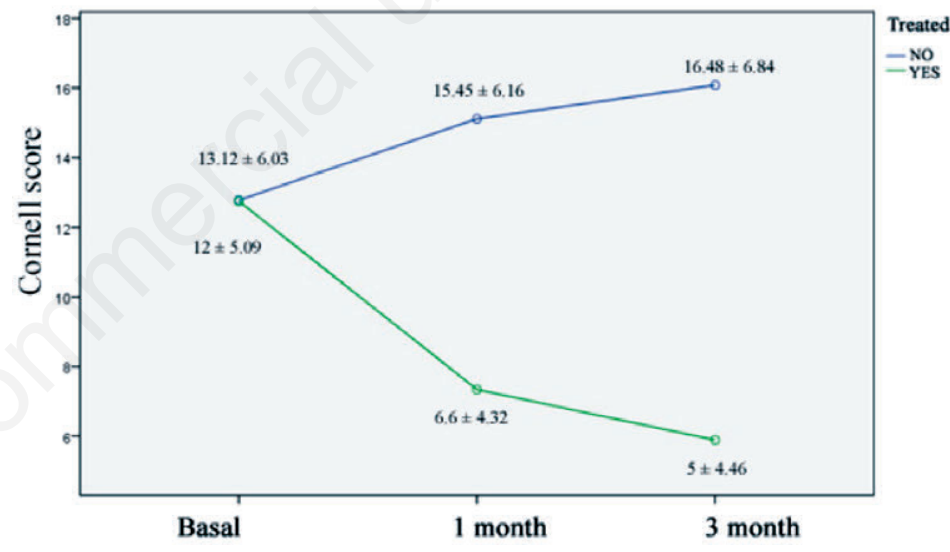

Figure 2. Cornell mean score. Lower is better.

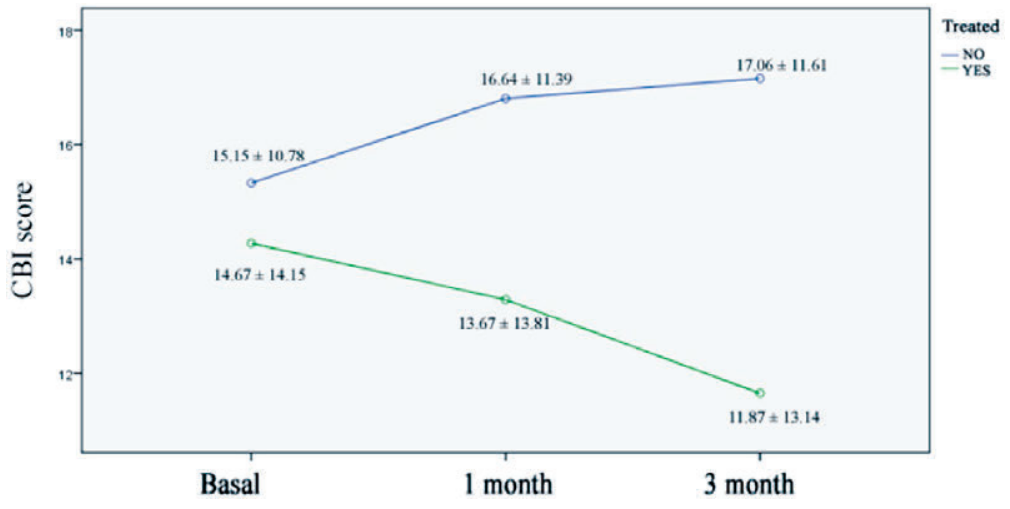

Figure 3. CBI mean score. Lower is better. 
A

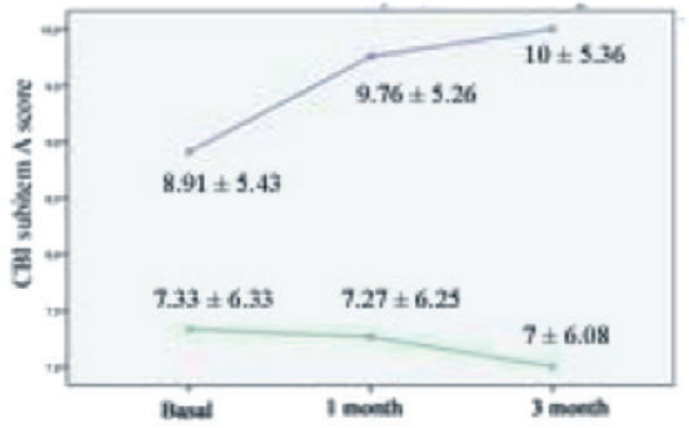

C

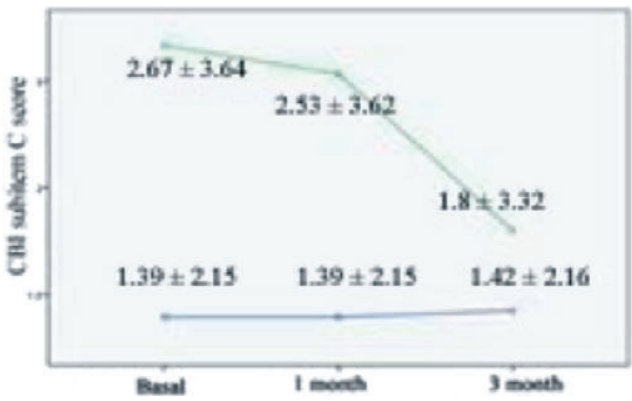

B $=$

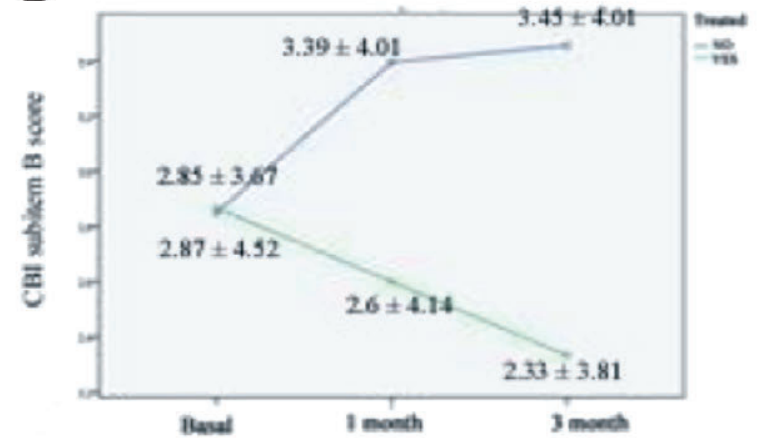

$\mathrm{D}$

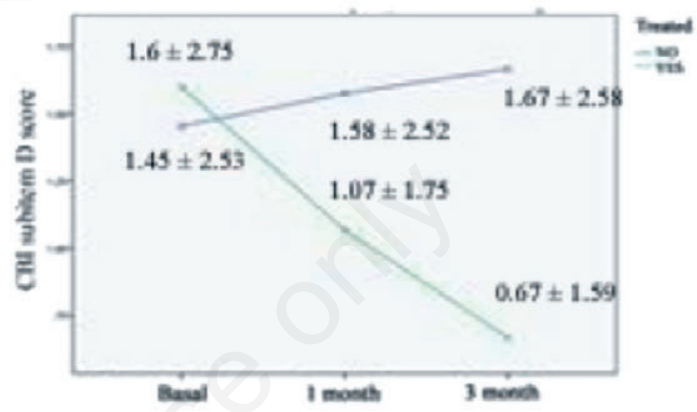

Figure 4. CBI subitems. Lower is better. A) Time; B) Development burden; C) Physical burden; D) Social burden.

A

\begin{tabular}{|c|c|c|c|}
\hline & CBI A & $\mathrm{N}$ & $\begin{array}{l}\text { mean score } \\
(\text { mean } \pm \mathrm{so})\end{array}$ \\
\hline \multirow{3}{*}{ Control } & Brsal & \multirow{3}{*}{33} & $8,91 \pm 5,433$ \\
\hline & 1 month & & $9,76 \pm 5,262$ \\
\hline & 3 month & & $10 \div 5,356$ \\
\hline \multirow{3}{*}{ Treated } & Bass & \multirow{3}{*}{15} & $7,33 \pm 6,332$ \\
\hline & 1 month & & $7,27 \pm 6,250$ \\
\hline & 3 month & & $7 \pm 6,083$ \\
\hline \multirow{3}{*}{ Total } & Basal & \multirow{3}{*}{48} & $8,42 \pm 5,709$ \\
\hline & 2 month & & $8,98 \pm 5,644$ \\
\hline & 3 month & & $9,06 \pm 5,703$ \\
\hline
\end{tabular}

C

\begin{tabular}{|c|c|c|c|}
\hline & $C B I C$ & $\mathbf{N}$ & $\begin{array}{l}\text { mean score } \\
\text { (mean } \pm \text { SD) }\end{array}$ \\
\hline \multirow{3}{*}{ Control } & Basal & \multirow{3}{*}{33} & $1,39 \pm 2,15$ \\
\hline & 1 month & & $1,39 \geq 2,15$ \\
\hline & 3 month & & $1,42 \pm 2,166$ \\
\hline \multirow{3}{*}{ Treated } & Basal & \multirow{3}{*}{15} & $2,67 \pm 3,638$ \\
\hline & 1 month & & $2,53 \pm 3,623$ \\
\hline & 3 month & & $1,8 \pm 3,321$ \\
\hline \multirow{3}{*}{ Total } & Basal & \multirow{3}{*}{48} & $1,79 \pm 2,729$ \\
\hline & 1 month & & $1,75 \pm 2,709$ \\
\hline & 3 month & & $1,54=2,551$ \\
\hline
\end{tabular}

B

\begin{tabular}{|c|c|c|c|}
\hline & CBI B & $N$ & $\begin{array}{l}\text { mean score } \\
\text { (mean } \div \text { SD) }\end{array}$ \\
\hline \multirow{3}{*}{ Control } & Basal & \multirow{3}{*}{33} & $2,85 \pm 3,675$ \\
\hline & 1 month & & $3,39 \pm 4,015$ \\
\hline & 3 month & & $3,45 \geq 3,985$ \\
\hline \multirow{3}{*}{ Treated } & Basal & \multirow{3}{*}{15} & $2,87 \div 4,518$ \\
\hline & 1 month & & $2,6 \pm 4,137$ \\
\hline & 3 month & & $2,33 \pm 3,811$ \\
\hline \multirow{3}{*}{ Total } & Basal & \multirow{3}{*}{48} & $2,85+3,908$ \\
\hline & 2 month & & $3,15=4,026$ \\
\hline & 3 month & & $3,10 \pm 3,926$ \\
\hline
\end{tabular}

D

\begin{tabular}{|c|c|c|c|}
\hline & $C B I D$ & $\mathrm{~N}$ & $\begin{array}{l}\text { mean score } \\
\text { (mean } \neq \text { SO) }\end{array}$ \\
\hline \multirow{3}{*}{ Control } & Basal & \multirow{3}{*}{33} & $1,45 \pm 2,526$ \\
\hline & 1 month & & $1,58 \pm 2,525$ \\
\hline & 3 month & & $1,67 \pm 2,582$ \\
\hline \multirow{3}{*}{ Treated } & Basal & \multirow{3}{*}{15} & $1,60 \pm 2,746$ \\
\hline & 1 month & & $1,07 \pm 1,751$ \\
\hline & 3 month & & $0,67 \geq 1,589$ \\
\hline \multirow{3}{*}{ Total } & Basal & \multirow{3}{*}{48} & $1,5 \pm 2,568$ \\
\hline & 1 month & & $1,42 \pm 2,305$ \\
\hline & 3 month & & $1,35 \pm 2,347$ \\
\hline
\end{tabular}

Figure 5. CBI mean scores. Lower is better. A) Time, $F=5.29 \mathrm{P}<0.007$; B) Development burden, $\mathrm{F}=6.464 \mathrm{P}<0.002$; $\mathrm{C}) \mathrm{Physical}$ burden, $\mathrm{P}<0.001$; D) Social burden, $\mathrm{F}=\mathbf{6 . 0 2 5} \mathrm{P}<\mathbf{0 . 0 0 3}$. 
be temporary and only present on the day following each music therapy session..$^{72}$ Differences in results may stem from the type of intervention: active $v s$ passive, individual $v s$ group sessions, relaxation music $v s$ pop music, etc. Further studies with large sample sizes and solid methodology should aim to explore the impact of these variables on treatment outcomes.

Our data did not consider functional dependence; the literature reports that music has no impact on that.

Although our results maight be influenced by the esiguity of the study sample and by the fact that most participants were women, we conclude that music therapy seems to have positive effect on caregiver burden and reduces apathy and depression in elderly subject with $\mathrm{AD}$ or VaD. Further controlled and methodologically welldesigned studies with homogenous samples are necessary to support the use of this tecnique, to rule out any placebo effect and analyse any residual long-term benefits.

\section{Conclusions}

According to the scientific literature examined the results of this study are consistent with the efficacy of receptive music interventions on improving apathy and depression in $\mathrm{AD}$ or $\mathrm{VaD}$ elderly patients and lowering associated caregiver's burden.

\section{References}

1. World Alzheimer Report; 2015.

2. Lyketsos C. Position statement of the American Association for Geriatric Psychiatry regarding principles of care for patients with dementia resulting from Alzheimer's Disease. Am J Geriatr Psychiatr 2006;14:561-72.

3. SIGN. Dementia Guidelines; 2006. Available from: http:/www.sign.ac.uk/ pdf/sign 86 pdf

4. Selbæk G, Engedal K, Bergh S. The prevalence and course of neuropsychiatric symptoms in nursing home patients with dementia: a systematic review. J Am Med Dir Assoc 2013;14: 161-9.

5. Marin RS. Apathy: a neuropsychiatric syndrome. J Neuropsychiatry Clin Neurosci 1991;3:243-54.

6. Robert P, Onyike CU, Leentjens AFG, et al. Proposed diagnostic criteria for apathy in Alzheimer's disease and other neuropsychiatric disorders. Eur Psychiatry 2009;24:98-104.
7. Mulin E, Leone E, Dujardin K, et al. Diagnostic criteria for apathy in clinical practice. Int J Geriatr Psychiatry 2011; 26:158-65.

8. Levy R, Dubois B. Apathy and the functional anatomy of the pre- frontal cortex-basal ganglia circuits. Cereb Cortex 2006;16:916-28.

9. Cipriani G, Lucetti C, Danti S, Nuti A. Apathy and dementia. Nosology, assessment and management. J Nerv Ment Dis 2014;202:718-24.

10. Ruthirakuhan M, Herrmann N, Abraham E, Lanctôt K. Pharmacological interventions for apathy in Alzheimer's disease (Protocol). Cochrane Databse Syst Rev 2016 [Epub ahead of print].

11. Kaufer D. Beyond the cholinergic hypothesis: the effect of metrifonate and other cholinesterase inhibitors on neuropsychiatric symptoms in Alzheimer's disease. Dement Geriatr Cogn Disord 1998;9:8-14.

12. Mitchell RA, Herrmann N, Lanctôt KL. The role of dopamine in symptoms and treatment of apathy in Alzheimer's disease. CNS Neurosci Ther 2011;17:41127.

13. Robert G. Apathy in patients with Parkinson disease without dementia or depression: A PET study. Neurology 2012;79:1155.

14. Silver J. Are you motivated to treat apathy? Am J Geriatr Psychiatry 2010 [Epub ahead of print].

15. Lanctôt KL, Herrmann N, Rothenburg L, Eryavec G. Behavioral correlates of GABAergic disruption in Alzheimer's disease. Int Psychogeriatr 2007;19:151-8.

16. Clarke DE, Ko JY, Kuhl EA, et al. Are the available apathy measures reliable and valid? A review of the psychometric evidence. J Psychosom Res 2011;70:73-97.

17. Steffens DC. Late-life depression and the prodromes of dementia. JAMA Psychiatr 2017 [Epub ahead of print].

18. American Psychiatric Association. Diagnostic and Statistical Manual of Mental Disorders. 5th edition. Washington, DC: American Psychiatric Association; 2013.

19. Naismith SL, Norrie LM, Mowszowski L, Hickie IB. The neurobiology of depression in later-life: clinical, neuropsychological, neuroimaging and pathophysiological features. Prog Neurobiol 2012;98:99-143.

20. Sexton CE, Mackay CE, Ebmeier KP. A systematic review and metaanalysis of magnetic resonance imaging studies in late-life depression. Am J Geriatr Psychiatry 2013;21:184-95.

21. Alexopoulos GS. Depression in the elderly. Lancet 2005;365:1961-70.
22. Krishnan KR, Taylor WD, McQuoid $\mathrm{DR}$, et al. Clinical characteristics of magnetic resonance imaging-defined subcortical ischemic depression. Biol Psychiatry 2004;55:390-7.

23. Pimontel MA, Reinlieb ME, Johnert LC, et al. The external validity of MRIdefined vascular depression. Int J Geriatr Psychiatry 2013;28:1189-96.

24. Minino AM, Arias E, Kochanek KD, Murphy SL, Smith BL. Deaths: final data for 2000. Natl Vital Stat Rep 2002;50:1-119.

25. Singh-Manoux A, Dugravot A, Fournier A, et al. Trajectories of depressive symptoms before diagnosis of dementia: a 28-year follow-up study. JAMA Psychiatr 2017 [Epub ahead of print].

26. Zubenko GS, Zubenko WN, McPherson $\mathrm{S}$, et al. A collaborative study of the emergence and clinical features of the major depressive syndrome of Alzheimer's disease. Am J Psychiatry 2003;160:857-66.

27. Lopez OL, Becker JT, Sweet RA, et al. Psychiatric symptoms vary with the severity of dementia in probable Alzheimer's disease. J Neuropsychiatry Clin Neurosci 2003;15:346-53.

28. Park JH, Lee SB, Lee TJ, et al. Depression in vascular dementia is quantitatively and qualitatively different from depression in Alzheimer's disease. Dement Geriatr Cogn Disord 2007;23:67-73.

29. Ballard C, Neill D, O'Brien J, et al. Anxiety, depression and psychosis in vascular dementia: prevalence and associations. J Affect Disord 2000;59:97-106.

30. Ismail Z, Elbayoumi H, Fischer CE, et al. Prevalence of depression in patients with mild cognitive impairment: a systematic review and meta-analysis. JAMA Psychiatry 2016 [Epub ahead of print].

31. Alexopoulos GS. Vascular disease, depression, and dementia. J Am Geriatr Soc 2003;51:1178-80.

32. Butters MA, Young JB, Lopez O, et al. Pathways linking late-life depression to persistent cognitive impairment and dementia. Dialogues Clin Neurosci 2008;10:345-57.

33. Alexopoulos GS. The vascular depression hypothesis: 10 years later. Biol Psychiatry 2006;60:1304-5.

34. Sheline YI, Price JL, Vaishnavi SN, et al. Regional white matter hyperintensity burden in automated segmentation distinguishes late-life depressed subjects from comparison subjects matched for vascular risk factors. Am J Psychiatr 2008;165:524-32.

35. Wolkowitz OM, Epel ES, Reus VI, Mellon SH. Depression gets old fast: do 
stress and depression accelerate cell aging? Depress Anxiety 2010;27:327-38.

36. Sierksma AS, van den Hove DL, Steinbusch HW, Prickaerts J. Major depression, cognitive dysfunction and Alzheimer's disease: is there a link? Eur J Pharmacol 2010;626:72-82.

37. van de Pol LA, Hensel A, Barkhof F, Gertz HJ, Scheltens P, van der Flier WM. Hippocampal atrophy in Alzheimer disease: age matters. Neurology 2006;66: 236-8.

38. Videbech P, Ravnkilde B. Hippocampal volume and depression: a meta-analysis of MRI studies. Am J Psychiatry 2004; 161:1957-66.

39. Colla M, Kronenberg G, Deuschle M, et al. Hippocampal volume reduction and HPA-system activity in major depression. J Psychiatr Res 2007;41:553-60.

40. Tokuchi R, Hishikawa N, Matsuzono K, et al. Cognitive and affective benefits of combination therapy with galantamine plus cognitive rehabilitation for Alzheimer's disease. Geriatr Gerontol Int 2015 [Epub ahead of print].

41. Rea R, Carotenuto A, Traini E, et al. Apathy treatment in Alzheimer's disease: interim results of the ASCOMALVA Trial. J Alzheimer's Dis 2015;48: 377-83.

42. Callegari I, Mattei C, Benassi F, et al. Agomelatine improves apathy in frontotemporal dementia. Neurodegener Dis 2016;16:352-6.

43. Rajkumar AP, Ballard C, Fossey J, et al. Apathy and its response to antipsychotic review and nonpharmacological interventions in people with dementia living in nursing homes: WHELD, a factorial cluster randomized controlled trial. J Am Med Dir Assoc 2016;17:741-7.

44. Leong C. Antidepressants for depression in patients with dementia: a review of the literature. Consult Pharm 2014;29:254-63.

45. Banerjee S, Hellier J, Dewey M, et al. Sertraline or mirtazapine for depression in dementia (HTASADD): a randomised, multicentre, double-blind, placebo-controlled trial. Lancet 2011; 378:403-11.

46. Nelson JC, Devanand DP. A systematic review and meta-analysis of placebocontrolled antidepressant studies in people with depression and dementia. J Am Geriatr Soc 2011;59:577-85.

47. Sepehry AA, Lee PE, Hsiung GY, et al. Effect of selective serotonin reuptake inhibitors in Alzheimer's disease with comorbid depression: a meta-analysis of depression and cognitive outcomes. Drugs Aging 2012;29:793-806.

48. Leyhe T, Reynolds CF 3rd, Melcher T, et al. A common challenge in older adults: Classification, overlap, and therapy of depression and dementia. Alzheimers Dement 2017;13:59-71.

49. Bruscia KE. Defining music therapy. Second. Gilsum, NH: Barcelona Publishers; 1998.

50. American Music Therapy Association. AMTA Member Sourcebook. Silver Spring, MD: American Music Therapy Association, Inc.; 2005.

51. Schmid W, Aldridge D. Active music therapy in the treatment of multiple sclerosis patients: a matched control study. J Music Ther 2004.

52. Pelletier CL. The effect of music on decreasing arousal due to stress: a metaanalysis. J Music Ther 2004;41:192-214.

53. Magill L. The use of music therapy to address the suffering in advanced cancer pain. J Palliat Care 2001;17:167-72.

54. Pedersen SKA, Andersen PN, Lugo $\mathrm{RG}$, et al. Effects of music on agitation in dementia: a meta-analysis. Front Psychol 2017;16:742.

55. Ballard CG. Management of agitation and aggression associated with Alzheimer disease. Nature Rev Neurol 2009;5:245-55.

56. Abraha I, Rimland JM, Trotta FM, et al. Systematic review of systematic reviews of non-pharmacological interventions to treat behavioural disturbances in older patients with dementia. The SENATOR-OnTop series. BMJ Open 2017;7:e012759.

57. van der Steen JT, van Soest-Poortvliet MC, van der Wouden JC, et al. Musicbased therapeutic interventions for people with dementia. Cochrane Database Syst Rev 2017;5:CD003477.

58. McKhann GM. The diagnosis of dementia due to Alzheimer's disease: Recommendations from the National Institute on Aging - Alzheimer's Association workgroups on diagnostic guidelines for Alzheimer's disease. Alzheim Dement J Alzheim Assoc 2011;7:263-9.

59. Sachdev P, Kalaria R, O'Brien J, et al. International Society for Vascular Behavioral and Cognitive Disorders Diagnostic criteria for vascular cognitive disorders: a VASCOG statement. Alzheimer Dis Assoc Disord 2014;28: 206-18.

60. American Psychiatric Association. Diagnostic and statistical manual of men- tal disorders (5th ed.). Arlington, VA: American Psychiatric Publishing; 2013.

61. Folstein MF, Folstein SE, McHugh PR. Mini-mental state. A practical method for grading the cognitive state of patients for the clinician. J Psychiatr Res 1975;12:189-98.

62. Marin RS. Apathy: concept syndrome neural mechanisms and treatment. Semin Clin Neuropsychiatr 1996;1:304-14.

63. Ready RE, Ott BR, Grace J, Fernandez I. The Cornell-Brown scale for quality of life in dementia. Alzheimer Dis Assoc Disord 2002;16:109-15.

64. Novak M, Guest CI. Application of a multidimensional care-giver burden inventory. Gerontologist 1989;29:798803.

65. Suzuki M, Kanamori M, Watanabe M, et al. Behavioral and endocrinological evaluation of music therapy for elderly patients with dementia. Nurs Health Sci 2004;6:11-8.

66. Irish M, Cunningham CJ, Walsh JB, et al. Investigating the enhancing effect of music on autobiographical memory in mild Alzheimer's disease. Dement Geriatr Cogn Disord 2006;22:108-20.

67. Ferreri L, Aucouturier JJ, Muthalib M, et al. Music improves verbal memory encoding while decreasing pre- frontal cortex activity: an fNIRS study. Front Hum Neurosci 2013;7:779.

68. Trainor LJ, Shahin AJ, Roberts LE. Understanding the benefits of musical training: effects on oscillatory brain activity. Ann N Y Acad Sci 2009;1169: 133-42.

69. Dassa A, Amir D. The role of singing familiar songs in encour- aging conversation among people with middle to late stage Alzheimer's disease. J Music Ther 2014;51:131-53.

70. Jantzen MG, Howe BM, Jantzen KJ. Neurophysiological evi- dence that musical training influences the recruitment of right hemispheric homologues for speech perception. Front Psychol 2014;5:171.

71. Takahashi T, Matsushita H. Long-term effects of music therapy on elderly with moderate/severe dementia. J Music Ther 2006;43:317-33.

72. Bruer RA, Spitznagel E, Cloninger CR. The temporal limits of cognitive change from music therapy in elderly persons with dementia or dementia-like cognitive impairment: a randomized controlled trial. J Music Ther 2007;44:308-28. 